\title{
A participação dos indígenas da banda meridional da capitania de Mato Grosso na Guerra do Paraguai
}

\author{
The involvement of Indians of the meridional side of Captaincy of Mato Grosso \\ in the Paraguayan War
}

La participación de los indígenas de la Banda Meridional de la Capitanía del Mato Grosso en la Guerra del Paraguay

Paulo Marcos Esselin*
Vera Lúcia Ferreira Vargas

\section{Resumo}

Desde o século XIX, tradicionalmente, diversos trabalhos que abordam a Guerra do Paraguai priorizam os aspectos da história militar, econômica e política do conflito. O presente artigo pretende analisar esse importante episódio da história do Brasil a partir da participação dos indígenas do sul de Mato Grosso no conflito, por meio de documentos oficiais produzidos pelo Estado brasileiro, relatos de viagens e memórias registradas por cronistas e viajantes.

Palavras-chave: Fronteira. Índios. Mato Grosso do Sul. Guerra do Paraguai.

\section{0 sul de Mato Grosso - \\ 0 s índios antes da guerra}

Na costa brasileira, no final do século XVI, os colonos portugueses substituíram o trabalho escravo do indígena pelo do negro africano, que se implantou a partir de uma estrutura econômica até então vinda de fora e que já havia incorporado vários elementos

Mestre em História pela Pontifícia Universidade
Católica do Rio Grande do Sul - PUCRS (1994).
Doutor em História pela PUCRS (2003). Pós-dou-
tor pela Universidade de São Paulo (2009). Profes-
sor associado II da Universidade Federal de Mato
Grosso do Sul. E-mail: paulo.esselin@gmail.com
* Mestre em História pela Universidade Federal de
Mato Grosso do Sul - UFMS (2003). Doutor em
História pela Universidade Federal Fluminense -
UFF (2011). Professora adjunta da Universidade
Federal de Mato Grosso do Sul. E-mail: veratere-
na@terra.com.br

Recebido em 25/03/2015 - Aprovado em 08/06/2015 http://dx.doi.org/10.5335/hdtv.15n.2.5647 
da cultura europeia e africana, excluindo, até onde foi possível, a contribuição dos povos nativos. Em Mato Grosso, ao contrário, o indígena desempenhou papel extremamente importante. $\mathrm{O}$ ano 1775 - ano da construção do forte Coimbra, que é um marco inicial da ocupação do Baixo Paraguai até 1834, quando efetivamente se iniciou a penetração das frentes colonizadoras de origem portuguesa na banda meridional - foi marcado pelo estreitamento das relações entre os nativos, colonos e militares, que iam se estabelecendo no território.

Nas proximidades do forte Coimbra, os comandantes estavam sempre preocupados em aldear os indígenas, atendendo às instruções de seus superiores:

Para dar meu parecer, conforme manda S.M. e V.Ex. me ordena, sobre o aldeamento dos índios uaicurús e guanás, que vivem como entre os portugueses, nos terrenos adjacentes, e a norte d'este presídio de Coimbra, e nos contíguos ao de Miranda, de tal fórma que fiquem sendo úteis a mineração e agricultura, confesso, Illlm e Exm. Sr. Que mais de uma vez tenho esforçado para cumprir esse meu dever (ALMEIDA SERRA, 1866, p. 240).

Instalados a longa distância da costa brasileira e dependendo de uma produção regular para manutenção das tropas estacionadas nos fortes, os portugueses recorreram aos nativos, que, desde o primeiro momento, foram aliciados ao uso de determinadas ferramentas mais produtivas, tais como machados e facões. Rapidamente, eles foram assimilando sua utilidade, e em troca de sua participação em frentes de trabalho, como a da extração da ipecacuanha, só lhes eram entregues alimentos.
O indígena foi sendo ensinado a usar técnicas mais sofisticadas, a manejar instrumentos mais adequados ao cultivo de plantas oriundas da Europa, introduzidas e adaptadas ao novo ambiente, e, assim, os vínculos entre nativos e colonos foram se estreitando.

Desde o final do século XVIII, fazia parte da estratégia das elites governamentais portuguesas e brasileiras a manutenção da integridade territorial do Brasil; a preocupação dos círculos governamentais era a de promover rapidamente a ocupação do território, no entanto, não havia população europeia suficiente para realizar com sucesso essa tarefa. Contava a colônia com uma população em torno de 3 milhões de habitantes; desses, 1 milhão eram escravos negros e 800 mil eram indígenas (GOMES, 2007). Embora a preferência dos dirigentes da província recaísse na colonização de origem alemã, por entender ser a mais laboriosa e disciplinada, eles mesmos a descartaram devido ao clima quente e insalubre impróprio para os povos daquela região da Europa (MOUTINHO, 1869).

Nesse contexto, não podendo contar com o africano devido aos limites impostos pelo modo de produção escravo, o índio passou a ser objeto de extremo interesse e importância para alcançar tal objetivo. Havia setores da elite brasileira e portuguesa que acreditavam que mesmo os índios bravos, considerados uma raça de homens naturalmente preguiçosa e, em grande parte, desagradecida e desumana, poderiam ser "civilizados" e prestar, a partir daí, relevantes serviços no processo de ocupação mercantil (ANDRADA e SILVA, 2000). Acreditava-se ainda que os nativos pudessem ser aldeados 
e que com o trabalho deles criar-se-iam condições para o desenvolvimento da agricultura e da pecuária mercantil, para o aumento da produção de gêneros alimentícios e para a criação de rebanhos por todo aquele vasto território. Assim, seriam promovidas a ocupação e a integração mercantis de todo o território do Brasil, bem como a estimulação do matrimônio entre nativos, brancos e mulatos das classes subalternizadas para misturar as raças e ligar os interesses recíprocos dos índios com os da gente vista como superior (ANDRADA E SILVA, 2000). Ou seja, a elite intentava introduzir elementos culturais ocidentais "civilizados" aos nossos naturais, enquanto se apossava dos territórios que eles ocupavam.

A situação econômica da província, no início do século XVIII, era de extrema decadência econômica; a crise da mineração com o esgotamento dos veios auríferos e diamantíferos levava ao deslocamento e à desmobilização de capitais e de mão de obra escravizada para regiões mais prósperas do Brasil. Entre 1819 e 1828, o número de trabalhadores escravizados retrocedeu de 14.180 para 12.715 trabalhadores, e no fim do ano de 1872, eles eram apenas 6.667 indivíduos (CORRÊA, 1976, p. 127). Não havia alternativas aos dirigentes provinciais que não fossem os povos nativos; os colonos estrangeiros não se interessariam por uma região tão distante da costa, as vias de comunicação e de transporte eram extremamente rústicas; a tudo isso acrescentava-se ainda a crônica falta de capitais, que são a alavanca de qualquer empreendimento significativo. Para instalação e ampliação de atividades mer- cantis, não havia alternativa que não fosse o aproveitamento dos povos autóctones.

Assim, em 1846, na província de Mato Grosso e em outras, para iniciar o aceleramento do processo de conversão dos nativos em homens "civilizados e produtivos", foi criada a Diretoria Geral dos Índios pelo Decreto de 24 de julho de 1845, chamado Regulamento das Missões, que colocou em prática uma vigorosa política de aldeamento. Surgiram, assim, as aldeias regulares: estabelecimentos oficiais nas províncias do Império. Cada núcleo era administrado por um diretor, religioso ou não, que estava subordinado ao diretor-geral da província. Na prática, não mudava muito a política que prevalecia desde os tempos coloniais. Esperava-se que os índios, uma vez aldeados, se tornassem dóceis e submissos aos costumes "civilizadores" do não índio e a uma cultura que não era a deles. Eram a catequese e a civilização propostas pelo Estado brasileiro para romper com a situação de "barbárie", e também uma porta aberta à exploração da mão de obra indígena por autoridades e fazendeiros. Assim, "civilizar" os povos indígenas representava, por fim, a "selvageria" de estabelecer uma "nova" sociedade, ou seja, "destruí-la enquanto formas inferiores e, no seu lugar, implantar outra, tida como superior" (ZORZATO, 1998, p. 185). Foi por esse viés que o Estado brasileiro conduziu a população autóctone.

Em discurso na abertura da Assembleia Legislativa provincial, em $1^{\circ}$ de março de 1837, portanto antes mesmo da criação da Diretoria Geral dos Índios, o presidente da província de Mato Grosso, referindo-se à catequese, afirma: 
Certamente nenhuma província do Brasil, Senhores, tem mais necessidade de um systema criador e esse respeito do que a de Mato Grosso, quer se olhe pelo lado de seus interesses especiais, quer pela face política, que apresenta como limitrophe, que tanto importa à Nação. Extrema, que comprehende quinhentas legoas de larga fronteira aberta a dous Governos extranhos, com mais de trinta optimos canaes, que desaguão nos fossos que formão suas primeiras linhas de defesa, quaes são os importantes rios Paraguay, Jaurú, Guaporé, Mamoré, e Madeira, e pelos quaes, assim como pode entrar - se pelo interior dos territórios daquelles Governos, póde - se também avançar até o interior do Brasil por muitos diferentes pontos, de nada se precisa tanto, como de população que lhe ministre força. E tanto mais vigorosa é esta necessidade, quanto exacto terem os estados vizinhos população muito superior sobre a fronteira e maior facilidade de trazer a ella os reforços de que precisem (BUENO, 1840, p. 171).

Na mesma ocasião, o presidente da província manifestava o seu reconhecimento à contribuição laboral que algumas nações autóctones davam ao progresso de Mato Grosso:

Muitas differentes nações de Indigenas vadeião os incultos e extensíssimos sertões da Provincia, em grandes porções ainda não trilhadas por nossa parte; de algumas temos notícia, de outras de que seguramente existem bem fundadas conjecturas: [...] Temos tirado não pequena vantagem para o serviço de defesa do Baixo Paraguay, dos guatos, Laianos, Terenos, Quinquenaos, e guánas (BUENO, 1840, p. 170).

Nas primeiras décadas do século XIX, os indígenas, sobretudo os Terena e os Guaná, tradicionais agricultores, eram livres e economicamente autônomos. Em contato com os religiosos que promoviam a catequese e com os soldados dos fortes instalados na fronteira, eles incorporaram novas práticas de cultivo e trabalho e instrumentos mais produtivos, ao ponto de se tornarem os responsáveis pela produção de hortifrutigranjeiros de alguns núcleos populacionais do sul do então Mato Grosso, como Miranda e Corumbá.

Joaquim Ferreira Moutinho, em visita à província, anos depois da criação da Diretoria Geral dos Índios, deixou registrado os progressos da catequese que realizaram os padres capuchinhos. Os Terena e os Laiana estavam aldeados sob a direção de frei Mariano de Bagnaia em uma bela planície, perto de Vila de Miranda, e prestavam relevantes serviços à sociedade já que cultivavam roças que abasteciam a vila de gêneros alimentícios. Em passagem pelo engenho de Piraputangas, propriedade do barão de Vila Maria, Moutinho deixou registrado que a esposa do barão oferecia aos índios diversas oficinas, que os habilitavam em diversos ofícios. Tornavam-se oleiros, remeiros e pilotos, empregavam-se em diversas atividades, inclusive no comércio, como camaradas nas canoas que transportavam gêneros para diversas localidades bem como nas fazendas de cultura e criação (MOUTINHO, 1869), ou seja, integravam o processo produtivo como trabalhadores subordinados.

O genovês Bartolomeu Bossi, que em 1862 passou pela banda meridional da capitania de Mato Grosso, deixou registrado que próximo da vila de Albuquerque, às margens do rio Paraguai, havia uma aldeia Guaná, cujos índios prestavam relevantes serviços à população local, tanto na agricultura como em outras necessidades e na pequena indústria (BOSSI, 1863). 
Nem todos os grupos nativos submeteram-se aos interesses dos colonizadores. Eles se relacionaram com o colonizador a partir de suas práticas culturais, que, em determinados grupos étnicos, consistiam no enfrentamento e, em outros, nos contatos amigáveis, de acordo com os seus próprios processos. Nesse sentido, alguns despertaram, pela resistência que ofereceram ao projeto de fixação de portugueses e espanhóis, as atenções das autoridades governamentais. Era o caso dos Guaicuru, a quem Bueno em meados do século XIX assim se referiu:

[...] no número das [dos povos indígenas] domesticadas não incluo a soberba intrépida nação dos Cavalleiros Guaicurús, sempre errante, e emprehendedora (BUENO, 1840, p. 170).

Os Mbayá/Guaicurú eram comunidades de caçadores, pescadores, coletores e horticultores muito incipientes. No período colonial, como não poderia deixar de ser, eram pedestres, adotando, a partir do século XVII, a domesticação e monta do cavalo introduzido pelos europeus, o que lhes permitia deslocamentos pelo chaco paraguaio, onde viviam. Durante todo o século XVI, e no começo do século XVII, eles viviam às margens ocidentais do rio Paraguai, ou seja, dentro do ambiente chaquenho (HERBERTS, 1998). Como caçadores, pescadores e coletores, eles necessitavam de grandes espaços territoriais para viver.

Na era pré-colonial, antes dos primeiros contatos, os Guaicuru estabeleciam diferentes relações (dominação, vassalagem, raptos, casamentos interétnicos ou trocas) com outras etnias de caçadores e coletores e os tradicionais agricultores, os Guaná (SIL-
VA, 2001). Raramente, atravessavam o Rio Paraguai, a não ser em investidas esporádicas, porque essa região era habitada pelos Guarani, Guaxarapó e outros grupos nativos contra quem faziam a guerra.

Os Guaicuru estabeleceram-se no Pantanal sul-mato-grossense no final do século XVII; oriundos do chaco paraguaio, passaram a habitar a região compreendida entre os rios Taquari e Jejui, território que passou a ser conhecido como "terra mbaianica", domínio do Mbayá/Guaicurú na designação brasileira (ASSIS BASTOS, 1972).

No início do século XVIII, os Mbayá/ Guaicurú passaram a atacar constantemente os paulistas que, em suas monções, seguiam pelas rotas dos rios de Mato Grosso em direção às minas de ouro de Cuiabá. Em 1719, eles aliaram-se aos Payaguá, canoeiros, e, desde então, passaram a atacar de barco, pelos rios, e a cavalo, por terra, os que penetravam seus territórios. Eles passaram a utilizar as canoas payaguá para os ataques $\mathrm{e}$ na maioria das vezes eram confundidos com os índios canoeiros (HERBERTS, 1998). Os Guaicurus impuseram duras derrotas aos paulistas em diversos ataques a comboios que se dirigiam a Cuiabá.

De 1725, quando ocorreu o primeiro grande confronto, até 1753, quando o último choque foi registrado, teriam sido mortos 4 mil intrusos, com uma perda de mais de 3 milhões (RODRIGO DO PRADO, 1856, p. 44). Mortalidade muito elevada, para o número de habitantes da província de Mato Grosso na época. Esses ataques contínuos ensejaram medo, insegurança, falta de suprimentos, fome e alta dos preços em Cuiabá (MOURA, 1984, p. 419). Devido às situações 
conflituosas estabelecidas entre nativos e forâneos nessa região, os ataques e as mortes de ambos os lados eram constantes e numerosos.

Embora os Guaicuru mantivessem o seu ímpeto guerreiro, em meados do século XIX, anos antes da Guerra da Tríplice Aliança, suas ações decaíam em relação às que motivaram dificuldades extremas ao processo de fixação tanto de portugueses como de espanhóis em Mato Grosso.

Na medida em que o processo de colonização foi se firmando na região, do lado espanhol, com a consolidação da cidade de Concepción e do forte de Bourbon, e do lado português, com os núcleos de Coimbra, Corumbá, Albuquerque e Miranda, configurou-se uma guerra tripartida entre espanhóis, lusitanos e Guaicuru. As duas potências europeias lutavam entre si por domínio e ampliação de suas fronteiras, enquanto os Guaicuru combatiam as duas, defendendo o seu território. A aliança de uma daquelas nações aos nativos tenderia a desequilibrar as forças. Aos poucos foi se delineando uma maior aproximação entre os índios Guaicuru e os portugueses, que culminou com o Tratado de Paz e Amizade, em 1791. Desde então, se desconhecem choques violentos entre os luso-brasileiros e os índios cavaleiros (COSTA, 2012).

A belicosidade guerreira dos Guaicuru foi substituída por trocas com as autoridades luso-brasileiras, o que sugeria também maior dependência dos produtos e das ferramentas de origem europeia. Assim, do ponto de vista dos europeus, após anos de convivência pacífica, os Guaicuru passaram de aliados senhoriais a simples nativos dominados, de negociantes de cavalos próprios e roubados a meros peões de fazenda (RIBEIRO, 1977, p. 82).

Do ponto de vista dos Guaicuru, estabeleciam-se relações comerciais sem as constantes ameaças e perseguições realizadas pelo Estado brasileiro. Aos poucos, foi desenvolvido um intenso trabalho de catequese, e, com isso, surgiram, ao redor dos fortes e das vilas, alguns aldeamentos que quebravam naturalmente a resistência dos nativos, também interessados em obter as vantagens que o Estado proporcionava aos seus aliados.

De outro modo, para os colonos espanhóis, os conflitos com os Mbayá generalizaram-se após o tratado de paz assinado com os luso-brasileiros e foram obrigados a enfrentar, então, constantes assaltos praticados nas estâncias e como represálias organizadas pelas autoridades assucenhas (CORREAA, 1999).

Foi nesse quadro de disputas e de acomodação que, no final de dezembro de 1864, as tropas paraguaias invadiram a província de Mato Grosso.

\section{Mato Grosso invadido}

Deflagrada a guerra de 1864-1870, entre o Paraguai, de um lado, e o Império do Brasil e as repúblicas da Argentina, sob o comando do unitário Bartolomé Mitre, e do Uruguai, sob a ditadura de Venancio Flores, de outro, as tropas paraguaias invadiram o sul do Mato Grosso com duas poderosas colunas, de 6 a 7 mil soldados, que, sob o comando dos coronéis Vicente Barrios e Isidoro Resquim, ocuparam o território entre os rios Apa e Branco, justamente uma área 
de ricos ervais, disputada pelo Brasil (BANDEIRA, 1998, p. 126).

As tropas paraguaias obtiveram pleno êxito na invasão de Mato Grosso com a primeira coluna, comandada pelo coronel Vicente Barrios, cunhado de Francisco Solano López, e ocuparam nas margens do Rio Paraguai o forte de Coimbra e as cidades de Albuquerque e Corumbá. A segunda coluna, comandada pelo coronel Isidoro Resquim, dominou a região entre o Rio Apa, a Serra de Maracaju e o Taquari, as colônias de Miranda e Dourados e as vilas de Nioaque e Miranda, estendendo-se ainda até Coxim.

As tropas imperiais encarregadas da defesa do território ofereceram pequena resistência, optando muito logo pela fuga, deixando forte, vila e território à mercê dos invasores. No dia 3 de janeiro de 1865, a Vila de Corumbá, onde se concentrava o maior contingente de militares, foi abandonada pelo comandante das armas, coronel Carlos Augusto de Oliveira, e pelo tenente-coronel Carlos de Moraes Camisão, junto com o $2^{\circ}$ Batalhão de Artilharia, do qual era comandante (CORRÊA, 1999, p. 146).

Quando da invasão paraguaia, alguns povos autóctones, principalmente os que se encontravam no sul de Mato Grosso, passaram a ter uma função importantíssima para a proteção e a garantia dos territórios do Brasil, ou melhor, para os territórios em que se encontravam as suas aldeias. Os nativos não podiam desertar de suas regiões com a mesma facilidade que os europeus. A primeira aldeia a ser atingida foi a de Bom Conselho, em Albuquerque, dos Kinikinau, cujos habitantes se dispersaram pela mata (VARGAS, 2003).
Em 1862, portanto antes do início das hostilidades entre Brasil e Paraguai, Moutinho, em visita ao aldeamento dos Kinikinau, deixara registrado que havia ali abundância de víveres cultivados, que os nativos se mostravam muito satisfeitos, os jovens já se comunicavam perfeitamente em idioma português e, com frequência, participavam das missas oferecidas pelos clérigos (MOUTINHO, 1869).

Já nas proximidades do forte e da vila de Miranda, sob a direção de frei Marianno de Bagnaia, estavam aldeados os Terena e os Laiana, que há muito prestavam serviços à comunidade, não só aos fazendeiros que se instalaram na região, como também cultivavam roças que abasteciam a vila e o forte com gêneros alimentícios (MOUTINHO, 1869). Nessa mesma região, também foram aldeados pelo frei Ângelo de Caramanico os Guarani-Kayoa (CORRÊA, 1999).

Antes que as tropas do exército paraguaio chegassem ao forte de Miranda, ele foi abandonado pelos militares e o depósito de artigos bélicos ficou entregue ao saque dos nativos aldeados nas proximidades. Antes de cair em poder dos paraguaios, como fatalmente aconteceria, os Terena, Laiana, Kinikinau, Kadiwéu e Baquio trataram de se prover de espingardas, clavinas e de quanta pólvora e bala quanto pudessem carregar. Munição de que dispuseram em abundância durante todo o tempo de ocupação do território (TAUNAY, 1931, p. 33). O comandante paraguaio Isidoro Resquim, mesmo chegando ao forte muito depois dos nativos, declarou ter arrecadado: "quatro peças, com seus carros de munição, 502 fuzis, 67 carabinas, 131 pistolas, 468 espadas, 1.092 lanças, 9.847 
projetis e artilharia de vários calibres" (FRAGOSO, 1934, p. 241). Esse enorme armamento, assim como o abandonado em Coimbra, Corumbá e outros pontos, sugere os projetos militares propostos para a província, em caso de guerra com o Paraguai.

Como aconteceu em Corumbá, com a deserção dos militares, a população imperial e as nativas da vila de Miranda ficaram entregues à própria sorte. À época da invasão, havia mais de dez aldeamentos fixos e regulares organizados em torno da vila, com aproximadamente 4 mil índios. Os Terena, em número superior a 3 mil, estavam estabelecidos em Naxedaxe, no Ipeguê e na Aldeia Grande, os Kinikinau no Agaxé, os Guaná no Eponadigo e no Lauiad, os Laiana, a meia légua da vila de Miranda (TAUNAY, 1948, p. 267).

Os nativos eram objeto de intenso trabalho de aldeamento e de catequese e prestavam serviços nos núcleos urbanos, mas foram abandonados ante a ameaça das tropas paraguaias à região, refugiando-se na Serra de Maracaju, lugar seguro no qual os paraguaios não se aventuravam (TAUNAY, 1931, p. 22-23). Havia também os cadiuéo que vagavam pelas regiões do Amagalabida e Nabilékê, também chamado Rio Branco, e os Guaicuru que estavam em acampamentos (e não em aldeias) no Lalima e perto de Nioaque (TAUNAY, 1948, p. 267).

Com base na pesquisa de Karl Von Den Steinen, nas atas da Diretoria dos Índios em Cuiabá, Mato Grosso, Boggiani (1975, p. 40) descreve que em 1848 havia uma população de índios Guaicuru assim distribuída: 850 cadiuéos no Paraguai, abaixo do forte Coimbra, quinhentos beaquéos e cotoguéos mo- rando, os primeiros, a leste do Paraguai e ao sul de Miranda, e os últimos em Lalima, seis léguas ao sul de Miranda, 130 guatiedeos em Albuquerque. Havia também os Guaicuru Cadiuéo, cerca de oitocentos, em ambas as margens do Paraguai, abaixo de Coimbra, divididos em diversas hordas. Moravam em tendas, viviam da caça e da pesca, não tendo lavouras. Mantinham muitos cavalos e gado bovino.

Os nativos reunidos na Serra de Maracaju prestaram relevantes serviços ao exército imperial, fornecendo homens, alimentos e guias. Tão logo ocorreu a invasão de Mato Grosso, as tropas paraguaias invadiram os aldeamentos indígenas e destruíram os cultivos que concorriam para o abastecimento da vila de Miranda e imediações, como também atearam fogo nos galpões que armazenavam os suprimentos. Com isso, desorganizou-se completamente a produção de víveres em toda a área invadida.

A malograda coluna militar imperial que partiu do Rio de Janeiro e se organizou em Uberaba, com o propósito de libertar o sul de Mato Grosso, imortalizada no livro A retirada da Laguna, de Visconde de Taunay, viveu enormes privações devido à completa ausência de alimentos. Dependendo de recursos que permitissem seus movimentos, ela foi gravemente prejudicada porque não teve renovados os seus estoques com a rapidez exigida. $\mathrm{O}$ gado muito arisco, fugia de maneira que os soldados ficavam reduzidos a chupar o miolo da palmeira imbocayá que os nativos denominavam mamuculi (TAUNAY, 1929, p. 17). Para que se entenda melhor as dificuldades pelas quais passaram os soldados e oficiais, no começo do 
ano de 1866, eles recebiam apenas a carne simples, com diminuta distribuição de sal (TAUNAY, 1928b, p. 126; TAUNAY, 1929, p. 64). Entretanto, essa foi a situação pela qual passou a maior parte do exército paraguaio durante boa parte do conflito.

Ao abandonar suas aldeias, fugindo dos ataques dos exércitos invasores, os indígenas se juntaram à população não índia, embrenhando-se pela Serra de Maracaju e estabelecendo-se "na belíssima chapada que coroa aquela serra de grés vermelha" (TAUNAY, 1948, p. 268). Na fuga, reconhecem os descendentes dos antigos moradores da vila de Miranda, os bugres, como eram chamados pejorativamente os índios, desempenharam importante papel. "Eles iam à frente, eram os donos dos matos, os ouvidos acostumados a distinguir as distâncias e a aproximação do perigo" (NANTES, 1993, p. 17). Embora em grande maioria, como muitos, receavam libertar-se com estrondo e crueldade da tutela ferrenha e abusiva em que sempre haviam sido conservados; mostraram-se mais independentes, mas nem por isso praticaram desmandos e crimes que teriam ficado impunes (TAUNAY, 1948). Houve, porém, parcialidades que se mantiveram à margem do confronto e outras que passaram a atacar ambos os lados, paraguaios e imperiais. Elas não serão abordadas no presente artigo.

A área escolhida pelos indígenas para erigir o povoado dos fugitivos era formada por uma densa floresta virgem, cujo solo era extremamente fértil. A princípio, tiveram os fugitivos que se contentar com uma dieta frugal de frutas nativas, palmitos, cocos da mata, mel de abelhas, caça e pesca. Os nativos, com grande conhecimento dos recursos da Serra de Maracaju, puderam disponibilizar os alimentos necessários para manter milhares de pessoas (NANTES, 1993). Logo, derrubaram área expressiva e passaram a cultivar o solo, obtendo, em seguida, boas colheitas. Segundo Taunay (1948), em março de 1867, o fornecimento de víveres já havia se regularizado. Eles completavam a dieta, aproveitando os estoques de gado bovino espalhados pelas pastagens naturais em torno da vila de Miranda. Transpunham a Serra e:

Por entre rondas passavam à noute quando desciam da serra para virem lançar reses na planície e ajouja-las com bois mansos, tangendo-as assim para o alto dos acampamentos. E com estas expedições repetidas sempre com êxito, apesar da vigilância dos inimigos, abasteciam-se de carne fresca, ou então seca ao sol, e ao ar (o que chama carne de vento) os moradores dos Morros. Só se podiam então queixar da falta de sal, esta mesma, até certo ponto, minorada pela exploração, embora imperfeitíssima, dos barreiros ou terrenos salitrosos, tão abundantes de matéria salina numerosos nesse sul de Mato Grosso (TAUNAY, 1948, p. 270-271).

Embora os autóctones desempenhassem importante papel na região dos morros onde se concentraram os dispersos da vila de Miranda, em maioria númerica, eles acabaram por arcar com praticamente todas as atividades de organização da produção. Eles continuaram, portanto, como antes, a prestar todo tipo de serviços à população não nativa e às tropas imperiais. Não se tratou, portanto, jamais de uma submissão plenamente voluntária, como propõem tantos autores atuais. Mas uma continuação, em situação extraordinária, da antiga submissão em que eram mantidos. Sobre tal realidade, Taunay é claro: 
Estamos na mais extraordinária das situações; o comandante obriga os pobres índios Terenas e Quiniquinaus a trabalharem sem trégua, apesar da necessidade em que estão de ir cultivar suas terras e sustentar as infelizes famílias. Sem razão alguma retém estes pobres coitados despachando escoltas para os prender. Desde que mostrem pouca vontade de vir submeter-se ao seu arbítrio (TAUNAY, [s.d.], p. 196).

Desde que iniciaram os combates, os nativos participaram por conta própria ou comandados por algum oficial do exército imperial. Quando da invasão das tropas paraguaias, que tiveram como alvo o forte de Coimbra, dez índios Kadiwéu, sob o comando do capitão Lixagota, juntaram-se à guarnição de Coimbra e, por dois dias, ofereceram pequena resistência aos intentos das tropas invasoras (RIO BRANCO, 1928 apud FRAGOSO, 1934). O tenente-coronel Porto Carreiro, comandante do forte, decidiu, depois de dois dias de combates, abandonar a posição, alegando falta de munição, encontrada dentro das muralhas em grande quantidade pelos paraguaios. Os Kadiwéu seguiram com as tropas para Corumbá, e de lá se dispersaram em fuga.

Foram os Terena e os Guaná que passaram a emboscar soldados paraguaios após terem destruído as suas roças de alimentos. Quando a coluna expedicionária imperial organizada para libertar o sul do Mato Grosso deixou Coxim em direção à Miranda, passou diante de um importante vestígio da invasão paraguaia,

[...] uma paliçada de grossos paus de aroeira com canhoneiras nos flancos, que servia de defesa contra os ataques dos nativos, lançados diversas vezes contra os paraguaios (TAUNAY, 1866, p. 275).
Os nativos costumavam invadir os acampamentos de paraguaios para roubar cavalos, enfraquecendo-os assim (TAUNAY, 1929). Nesse sentido, foram várias as ações dos índios em defesa do território, ao lado do exército imperial.

Em outra ocasião, no porto de Maria Domingas sobre o Aquidauana, os Laiana estavam entregues à tarefa de cortar canas quando pressentiram a presença de uma patrulha paraguaia. Seriam em torno de vinte soldados. De pronto, os indígenas embrenharam na alta lavoura e aguardaram a aproximação dos invasores. Quando eles se aproximaram dos nativos, de súbito, irrompia a fuzilaria indígena. Foram abatidos oito soldados paraguaios (ALMEIDA, 1951). A pequena resistência que os exércitos paraguaios encontraram no sul da província de Mato Grosso foi quase que exclusivamente oferecida pelos indígenas.

Tão logo os contingentes da força expedicionária chegaram à Serra de Maracaju, onde se concentrava o maior número de refugiados da vila de Miranda e das aldeias do entorno, os oficiais organizaram um alistamento para recrutar os nativos para o serviço militar. Os índios foram convocados a se apresentarem às autoridades militares e se juntarem à força que iria enfrentar os exércitos invasores. Foram reunidos

[...] em um primeiro alistamento duzentos e dezesseis terenas, trinta e nove kinikinaus e vinte laianas. Os Guaicuru, através do seu capitão Nadô, firmaram o compromisso de se juntarem com todos os seus guerreiros ao Exército imperial (TAUNAY, 1929 , p. 130). 
Quando as tropas imperiais invadiram uma pequena porção do território do Paraguai, até a fazenda da Laguna, destacou-se o empenho dos Terena e dos Guaicuru, que, "depois de se comportarem como bravos auxiliares, carregavam aos ombros os despojos dos cavalos tomados dos paraguaios" (TAUNAY, 1928a, p. 60). Nos documentos oficiais sobre a retirada da Laguna, consta na ordem do dia, do major de comissão José Tomás Gonçalves, comandante do batalhão $\mathrm{n}^{\circ} 21$ de Infantaria, o seguinte informe:

Os índios Guaycuru e Terêna, desmentindo a opinião infundada que deles faz-se geralmente, portaram-se com muita coragem, tornando-se digno de consideração [...]. Avançando a peito descoberto desalojaram o inimigo de um bosquezinho, fazendo nele grande mortandade (TAUNAY, 1928a, p. 192-193).

A infeliz coluna imperial ainda teve que contar com a ajuda dos nativos como tradutores e guias. Os engenheiros que participaram do conflito elaboraram a carta do território sul-mato-grossense, examinando o curso dos rios, o relevo, os acidentes geográficos, os rios que tinham águas calmas e navegáveis e ofereciam fácil travessia, enfim, reunindo informações importantes da província que era completamente desconhecida das autoridades nacionais e provinciais. Para se ter ideia da dependência que as autoridades tinham dos povos nativos, em novembro de 1863, o presidente da província de Mato Grosso, Augusto Leverger, foi encarregado pelo governo imperial da coordenação e do complemento da Carta de Mato Grosso. No mês de agosto daquele mesmo ano, ele ficou por alguns dias na vila de Mi- randa à espera de um guia Kadiwéu para acompanhá-lo na tarefa de explorar as zonas sul e sudoeste de Mato Grosso, pois os índios dessa etnia eram exímios conhecedores da região. Sem eles era praticamente impossível a qualquer autoridade se deslocar com sucesso pela província (ALMEIDA, 1951).

Devido ao conhecimento do território, os nativos foram importantes informantes, permitindo com seus relatos que as autoridades imperiais monitorassem os movimentos dos paraguaios em todo o período de invasão, mesmo que não se tivesse sido feito muito com essa informação para a reconquista dos territórios. Em 24 de julho, por exemplo, alguns nativos vindos da fronteira do baixo Paraguai passaram notícias sobre o número de forças inimigas e a quantidade de navios estacionados em Corumbá (COSTA, 2012).

Com o final da guerra, era necessário reorganizar o território brasileiro e proteger suas fronteiras; novamente os povos indígenas desempenhariam uma função importante para a reconstrução dos territórios destruídos pelo conflito, especialmente no sul da província, onde se iniciava o povoamento por não índios (VARGAS, 2003). Nesse sentido, o documento da Diretoria Geral dos Índios, de 1871, evidencia a situação na qual se encontrava o então distrito de Miranda bem como o interesse das autoridades brasileiras e dos regionais em relação às terras e à mão de obra indígena para a reconstrução do território. Mais uma vez, o nativo era visto pragmaticamente como elemento fundamental na reorganização mercantil da região, como fornecedor de mão de obra, de produtos e serviços: 
VEx ${ }^{a}$ conhece o estado de anniquilação completa a que forão reduzidos a villa e todo districto de Miranda, que o Diretor dos índios daquellas aldeas, Frei Mariano de Bagnaia foi prisioneiro dos paraguayos até quase o fim da guerra, e que hoje é vigário do Corumbá, onde reside, não podendo por isso tomar promptas providências a favor daquelles índios, e nem informar a Diretoria a cerca de ocorrencias que dão naquellas aldeas. Agora, porem que existe no logar de Miranda um Corpo de tropas, e que por alli vão affluindo da devastação, parece-me consciente que V.Ex ${ }^{a}$. recommende ao comandante militar e as autoridades do logar toda proteção a favor dos índios, e que os mantinha em suas terras, visto como serão precisos ainda annos para que Miranda volte ao seo antigo estado, e tenha as autoridades próprias de uma villa. Se não houver grande repugnancia da parte dos índios convirá reunil-os em uma só aldea, no que haverá grande proveito para elles e para a sociedade, e isto pode V.Ex ${ }^{\mathrm{a}}$. recomendar ao commandante militar (BRASIL, 1873, p. 79).

De acordo com essas afirmações, o então diretor geral dos índios, Antônio Luiz Brandão, apresentou os problemas que enfrentavam, naquele momento, os índios, os territórios que ocupavam e a possível solução. Essa situação prolongou-se por anos, e a solução encontrada foi mais uma vez aldeá-los de acordo com o modelo estabelecido pelo regulamento das Missões de 1845; com essa ação, a política indigenista interrompida pela mencionada guerra estava sendo retomada nesse novo contexto político e territorial. Isso representava aldear os índios indistintamente em pequenas áreas, insuficientes para o seu desenvolvimento econômico, físico e cultural, o que abria espaço para novas fazendas e roças europeias. Essa era a proposta para resolver o problema de terras que atenderia aos interesses do governo, e não aos dos indígenas.

Como foi possível constatar, embora tendo os nativos uma atuação destacada na frente de guerra e na resistência, nem por isso deixaram de sofrer todo tipo de preconceito e desrespeito. Quando o conflito terminou e os fugitivos da Serra de Maracaju retornaram aos seus lares, passaram a publicar os registros de suas experiências vividas naquele período de sofrimento e sacrifícios, e não deixaram de manifestar suas opiniões a respeito das etnias indígenas com as quais conviveram por longos cinco anos. Obviamente, foram obrigados a reconhecer que eles foram fundamentais para garantir a sobrevivência de todos os que se homiziaram das tropas invasoras, período, na opinião deles, marcado por um incontido pânico e perplexidade; episódios tristes, de muita aflição, amargos e de profunda insegurança.

O medo era tanto que eles [os habitantes da vila de Miranda] nem procuravam saber se a notícia era verdadeira.

Era preciso largar tudo e fugir para o mato! Alguém se pendurou no sino da igreja já que se pôs a tocar nervosamente. E gente corria para todos os lados. Alguns já com trouxas de roupas passavam aflitos, sem saber para onde ir (NANTES, 1993, p. 11).

Foram seguindo os passos seguros dos guias práticos que logo chegaram à primeira furna do morro, onde se sentiram seguros. Pelo caminho, os partos se sucediam, e eram realizados pelas bugras, assim eram chamadas as mulheres dos povos autóctones pelos não índios. Como a fuga se realizou às pressas, não conseguiram reunir alimento em quantidade que lhes permitisse passar mais 
que uma semana. No entanto, na serra, os nativos encontraram as condições possíveis de sobrevivência.

Muitos dos alimentos eram obtidos por meio da pesca: o pintado, o pacu, o dourado, o jaú, o bagre, as arraias, as traíras, todos eram facilmente retirados dos rios. Da mata vinham as bocaiúvas, os pindós, os genipapos, a guavira, o jatobá, o caju do campo, o algodãozinho, o pequi, o ariticum, o maracujá, o tamarindo. Essas frutas típicas da mata os nativos também disponibilizavam a todos os fugitivos; com elas, ainda produziam mingaus e refeições variadas. Os fugitivos, assim, aprenderam com os bugres a comer o que encontravam, como carne de paca, veado, tatu, pato do mato, anhuma, assim como o mel da região, que passou a ser muito apreciado (NANTES, 1993). Certamente, não fossem os nativos, muitos fugitivos não teriam sobrevivido. Essa convivência forçada permitiu que os colonos aprendessem a língua dos nativos e adotassem alguns de seus costumes para viver melhor.

Muitos nativos prestaram todo tipo de trabalho aos não índios e protegeram os que se refugiaram na serra. Durante os anos de guerra, lutaram nas tropas imperiais. Entretanto, os cadiuéo continuaram a ser chamados de "bugres bravos", identificados de longe pelo "cheiro forte do bugre bravo" (NANTES, 1993, p. 22). As demais etnias não tiveram melhor aceitação, sendo também tratadas com extremo preconceito. Após enviuvar, um fazendeiro envolveu-se com algumas bugras e com elas teve muitos filhos. Revoltado, um dos filhos do primeiro casamento deixou de assinar o nome paterno e passou a usar o de seu padrinho, para não carregar como aquele bando de bugrinhos o sobrenome do seu progenitor (NANTES, 1993, p. 52).

\section{Consideracōes finais}

As tropas militares do império contaram com a auspiciosa contribuição dos povos nativos durante toda a Guerra do Paraguai. Embora eles tivessem participado ativamente da resistência ao lado dos vencedores, o saldo da conquista foi extremamente negativo. Antes mesmo do final da guerra, algumas epidemias potencialmente mortais, como a cólera e a varíola, atingiram toda a população, com destaque para os Guató e os Guaná, que tiveram uma acentuada redução populacional e a quase extinção de seus grupos. Com a preocupação exclusiva de proteger as fronteiras, as autoridades centrais e provinciais procederam o estímulo da ocupação não-índia do território e a criação de inúmeros postos militares ao longo da linha divisória. Muitos dos soldados do exército imperial que participaram da guerra, quando desmobilizados, estabeleceram-se na região, como também, migrantes oriundos das mais diversas regiões do Brasil. Foi grande a pressão sobre as terras e a mão de obra nativa.

Após o fim dos combates e a assinatura do tratado de paz, os nativos desceram a serra na expectativa de retomar as suas antigas aldeias, o que, entretanto, não foi possível, uma vez que elas haviam sido invadidas por fazendeiros e pelos migrantes que foram se estabelecendo em pleno território tradicional dos autóctones. Sem os seus territórios, a população indígena foi se dispersando pelas fazendas da região, na condição de vaquei- 
ros e agricultores. Logo se transformaram no principal elemento de trabalho nas fazendas que iam se organizando no sul de Mato Grosso, em terras que haviam sido suas. Os que haviam combatido os paraguaios eram agora derrotados pelos brasileiros.

O período do final da guerra representou para os povos indígenas, além da destruição de suas aldeias, a ocupação de seus territórios por não índios e a legalização de sua desterritorialização pelo governo brasileiro.

\section{Resumen}

Desde el siglo XIX, los diversos trabajos que abordan la Guerra del Paraguay tradicionalmente priorizan los aspectos de la Historia militar, económica y política del conflicto. El presente artículo pretende analizar este importante episodio de la Historia de Brasil a partir de la participación de los indígenas del Sur del Mato Grosso en el referido conflicto, por medio de documentos oficiales producidos por el Estado brasileño, relatos de viajes, memorias registradas por cronistas y viajeros.

Palabras clave: Frontera. Indígenas. Mato Grosso do Sul. Guerra del Paraguay.

\section{Abstract}

Since the XIX century, traditionally, many studies about the Paraguayan War provided priority for aspects of military history, and the economic and political conflicts. This work analyses that important episode of Brazilian History, from participation of the southern Indians of Mato Grosso in the conflict, through official documents produced by Brazilian State, travel reports, and recorded memories by chroniclers and travelers.

Keywords: Frontier. Indian. Mato Grosso do Sul. War of Paraguay.

\section{Referências}

ALMEIDA, Mário Monteiro. Episódios da formação geográfica do Brasil: fixação das raias com o Uruguai e o Paraguai. Rio de Janeiro: Pongetti, 1951.

ALMEIDA SERRA, Ricardo Franco. Parecer sôbre o aldêamento dos Uaicurús e Guanás, com a descripção dos seus usos, religião, estabilidade e costumes. Revista Trimestral de História e Geografia - ou jornal do Instituto Histórico e Geographico Brasileiro, Rio de Janeiro: Typographia de João Marcio da Silva, tomo VII, 2. ed., p. 240-276, 1866.

ANDRADA E SILVA, José Bonifácio. Projetos para o Brasil. São Paulo: Companhia das Letras; Publifolha, 2000.

ASSIS BASTOS, Uacury Ribeiro. Expansão territorial do Brasil colônia no Vale do Paraguai (1767-1801). 1972. 194f. Tese (Doutorado em História) - Faculdade de Filosofia Letras e Ciências Humanas, Universidade de São Paulo, São Paulo, 1972.

BANDEIRA, Moniz. O expansionismo brasileiro e a formação dos estados na Bacia do Rio da Prata: Argentina, Uruguai e Paraguai, da colonização a Guerra da Tríplice Aliança. 3. ed. Rio de Janeiro: Revan, 1998.

BOGGIANI, Guido. Os Caduveos. Belo Horizonte: Itatiaia, 1975.

BUENO, José Antônio Pimenta. Discurso proferido pelo Presidente da Província do Mato Grosso, o Doutor José Antônio Pimenta Bueno, na abertura da Assembléia Legislativa Provincial em $1^{\circ}$ de Março de 1837. Revista do Instituto 
Histórico e Geográfico Brasileiro, Rio de Janeiro, tomo II, p. 170-174, 1840.

COSTA, Maria de Fátima. Índios en la Guerra de la Triple Alianza. In: BORGES, Fernando Tadeu de Miranda; PERARO, Maria Adenir (Org.). Brasil e Paraguai: uma releitura da Guerra. Cuiabá: EDUFMT, 2012. p. 63-85.

BOSSI, Bartolomé. Viagem pitoresca pelos rios Paraná, Paraguai, S. Lourenço e Arinos e notícia descriptiva da província de Mato Grosso debaixo de seu aspecto physico, geográfico, etnographico, minerologico e produções naturaes. Paris: Livraria Parisiense, 1863. (Versão e notas de F. Artur Montenegro).

BRASIL. Diretoria Geral dos Índios. Doc. 1871, livro $\mathrm{n}^{\circ} 191$, v. 80, p. 79, 1873, APMT.

CORRÊA, Valmir Batista. Fronteira oeste. Campo Grande: UFMS, 1999.

Mato Grosso: 1817-1840 - e o papel da violência no processo de formação e desenvolvimento da província. 1976. Dissertação (Mestrado em História social) - Faculdade de Filosofia, Letras e Ciências Humanas, Universidade de São Paulo, São Paulo, 1976.

FRAGOSO, Tasso Augusto. História da Guerra entre a Tríplice Aliança e o Paraguai. Rio de Janeiro: Imprensa do Estado Maior do Exército, 1934. V. I.

GOMES, Laurentino. 1808: como uma rainha louca, um príncipe medroso e uma corte corrupta enganaram Napoleão e mudaram a história de Portugal e do Brasil. São Paulo: Planeta do Brasil, 2007.

HERBERTS, Ana Lúcia. Os Mbayá-Guaicuru: área, assentamento, subsistência e cultura material. 1998. 345f. Dissertação (Mestrado em História) - Programa de Pós-Graduação em História, Universidade do Vale do Rio dos Sinos, São Leopoldo, 1998.

MOURA, Carlos Francisco. Os Paiaguás, “índios anfíbios" do rio Paraguai. In: REUNIÃO INTERNACIONAL DE HISTÓRIA DA NÁU-
TICA E DA HIDROGRAFIA, 5, 1984, Rio de Janeiro. Atas... Rio de Janeiro, 1984. p. 419-487.

MOUTINHO, Joaquim Ferreira. Notícia sobre a província de Mato Grosso, seguida d' um roteiro de viagem de sua capital a São Paulo. São Paulo: Tpy Henrique Schroeder, 1869.

NANTES, Aglay Trindade. Morro Azul: estórias pantaneiras. Campo Grande: Rubens Aquino, 1993.

RIBEIRO, Darcy. Os índios e a civilização: a integração das populações indígenas no Brasil moderno. 2. ed. Petrópolis: Vozes, 1977.

RODRIGO DO PRADO, Francisco. História dos índios cavaleiros ou da nação Guaycurú. Revista do Instituto Histórico e Geographico do Brasil. Rio de Janeiro: Typografia Universal de Laemmert, 2. ed., tomo I, 1856.

SILVA, Veronice Cristina da. Missão, aldeamento e cidade. Os Guaná entre Albuquerque e Cuiabá (1819-1901). 2001. 145f. Dissertação (Mestrado em História) - Instituto de Ciências Humanas e Sociais, Universidade Federal de Mato Grosso, Cuiabá, 2001.

TAUNAY, Visconde de. A retirada da Laguna: episódio da Guerra do Paraguai. São Paulo: Companhia Melhoramentos, 1928a.

. Cartas da campanha de Matto Grosso. Rio de Janeiro: [s.n.], s.d.

Em Matto Grosso invadido 1866-1867. São Paulo: Companhia Melhoramentos, 1929.

. Entre os nossos índios. São Paulo: Companhia Melhoramentos de São Paulo, 1931.

. Marcha das forças: expedição de Matto Grosso. São Paulo: Companhia Melhoramentos, $1928 b$.

Memórias do Visconde de Taunay. São Paulo: Instituto Progresso, 1948.

Relatorio da Comissão de engenheiros desde o rio Taquary até a Vila de Miranda - com documentos annexos e trabalhos parciaes de alguns ajudantes da mesma commissão junto 
as forças em operações ao sul da provincia de Matto Grosso. 1866.

VARGAS, Vera Lúcia Ferreira. A construção do território Terena (1870-1966): uma sociedade entre a imposição e a opção. 2003. 160f. Dissertação (Mestrado em História) - Universidade de Mato Grosso do Sul, Dourados, 2003.

ZORZATO, Osvaldo. Civilizadores de Índios: os agentes do sertão na historiografia de Mato Grosso. Fronteiras, Campo Grande, v. 2, n. 4, p. 171-201, jul.-dez. 1998. 